\title{
Theories of biological aging: Genes, proteins, and free radicals
}

\author{
SURESH I.S. RATTAN \\ Laboratory of Cellular Ageing, Department of Molecular Biology, Danish Centre for Molecular Gerontology, University of \\ Aarhus, Aarhus-C, Denmark
}

Accepted by Dr T. Grune

(Received 15 fune 2006)

\begin{abstract}
Traditional categorization of theories of aging into programmed and stochastic ones is outdated and obsolete. Biological aging is considered to occur mainly during the period of survival beyond the natural or essential lifespan (ELS) in Darwinian terms. Organisms survive to achieve ELS by virtue of genetically determined longevity assuring maintenance and repair systems (MRS). Aging at the molecular level is characterized by the progressive accumulation of molecular damage caused by environmental and metabolically generated free radicals, by spontaneous errors in biochemical reactions, and by nutritional components. Damages in the MRS and other pathways lead to age-related failure of MRS, molecular heterogeneity, cellular dysfunctioning, reduced stress tolerance, diseases and ultimate death. A unified theory of biological aging in terms of failure of homeodynamics comprising of MRS, and involving genes, milieu and chance, is acquiring a definitive shape and wider acceptance. Such a theory also establishes the basis for testing and developing effective means of intervention, prevention and modulation of aging.
\end{abstract}

Keywords: Biogerontology, gerontogenes, molecular damage, stress, homeostasis, homeodynamics, hormesis, anti-aging

Abbreviations: FR, free radicals; ROS, reactive oxygen species; ELS, essential lifespan

\section{Introduction}

In a frequently cited paper from 1990, Zhores Medvedev had attempted to make a rational classification of theories of aging [1]. He counted more than 300 theories, none of which could qualify as being the theory of aging, and all of them could be, at best, labeled as "hypotheses" or "aspect theories". Over the years, gerontologists have become resigned to the futility of formulating a unified theory of aging which can encompass its evolutionary, biological, and sociological aspects. The main reason for the emergence of this pessimistic view is that the large body of descriptive data in gerontology underlines the multifaceted, diverse and complex nature of aging. Most significantly, it has been clearly shown that the phenotype and the rate of progression of aging are highly variable in different species, in organisms within a species, in organs and tissues within an organism, in cell types within a tissue, in sub-cellular compartments within a cell type, and in macromolecules within a cell. These observations necessarily lead to the conclusion that aging has no universal cause, phenotype, and consequence, except death.

However, the above conclusion does not imply that there cannot be any satisfactory, rational and scientific explanations for the origin, occurrence, progression and consequences of aging, and that aging is an unsolved or unsolvable problem in biology. To the contrary, as reasserted by Robin Holliday in his recently published article titled "Aging is No Longer an Unsolved Problem in Biology" [2], the biological basis of aging are well understood, and important general principles of aging and longevity can be

Correspondence: S. Rattan, Department of Molecular Biology, University of Aarhus, Gustav Wieds Vej 10C, DK8000 Aarhus-C, Denmark. Tel: 458942 5034. Fax: 458612 3178. E-mail: rattan@mb.au.dk 
derived, which can be the basis for future research and intervention towards achieving a healthy old age [3-7].

\section{Evolutionary principle of aging}

The evolutionary "life history principle" describes aging as an emergent phenomenon that takes place primarily in protected environments which allow survival beyond the natural lifespan in the wild. The natural lifespan of a species, termed "essential lifespan" (ELS) [4,7], or the "warranty period" [8], is the time required to fulfill the Darwinian purpose of life in terms of successful reproduction for the continuation of generations. Species that undergo fast maturation and have an early onset of reproduction with large reproductive potential generally have a short ELS, whereas slow maturation, late onset of reproduction, and small reproductive potential of a species is concurrent with its long ELS. For example, the ELS of Drosophila is less than a week as compared with that of about 50 years of Homo sapiens, even though in protected environments (laboratories and modern societies, respectively), a large proportion of populations of both species can and do live for much longer than that. Therefore, from an evolutionary point of view, ELS is the canvas against which the genetic selection and functional optimization unfold. (The biochemical and physiological basis of ELS will be discussed in a later section).

While detailed arguments about evolutionary explanations for the origin and occurrence of aging can be accessed in extensive writings of several authors (for example, see [9-12]), here it may be sufficient to point out that from evolutionary, biological and life history points of view, aging is considered to set in and manifest mainly during the period of extended survival beyond ELS.

\section{Molecular description of aging}

Biogerontologists and geriatric pathologists have gleaned a wealth of information regarding age-related changes at all levels of biological organization. While several of these age-related normal and pathological changes may be widely observed across species, other changes are specific to specific species, organs, systems, tissues, cells, organelles and macromolecules. Therefore, a major challenge for any theory of biological aging is to provide mechanistic explanations for the origin and occurrence of both "universal" and "specific" age-related changes, also termed "public" and "private" mechanisms, respectively [13]

Since the biological bases of all aging systems reside in the optimal functioning of molecules within a cell, it is useful to recapitulate what molecular changes happen during aging. Observational and descriptive studies performed on a large variety of aging systems have demonstrated that the main molecular characteristic of aging is the progressive accumulation of damages in macromolecules. Although different types of molecular damage accumulate at different rates and to different extents in different cells, the fact remains that there is a progressive increase in molecular heterogeneity with age. Table I gives a list of major categories of age-related damage in macromolecules, which have been observed during various cells, tissues and organs.

It is obvious that all small and big molecules are prone to damage, but the source and biological consequences of various molecular damage may vary widely, thus increasingly creating molecular heterogeneity. Furthermore, although the action of a damaging agent is essentially stochastic, the vulnerability of a macromolecule to the damaging agent may be dependent on its chemical sequence, structure and accessibility in the presence of several other interactive macromolecules. It is not simple to relate any particular kind of damage and its levels in the cells to a specific biological consequence, especially aging, pathology and survival.

\section{Molecular explanations of aging}

There are three major sources of damage within a cell: (1) reactive oxygen species (ROS) and free radicals (FR) formed due to external inducers of damage (for example ultra-violet rays), and as a consequence of cellular metabolism involving oxygen, metals and other metabolites; (2) nutritional glucose and its metabolites, and their biochemical interactions with ROS; and (3) spontaneous errors in biochemical processes, such as DNA duplication, transcription, post-transcriptional processing, translation, and post-translational

Table I. Main categories of molecular damage occurring during cellular aging.

\begin{tabular}{llc}
\hline Macromolecule & Examples of damage & Selected recent references \\
\hline DNA (nuclear and mitochondrial) & Mutations, epimutations, base modifications, & {$[14-18]$} \\
strand breaks & Base modifications, miscoding, missplicing & {$[19]$} \\
Protein & Amino acid modifications, misincorporation, & {$[19-25]$} \\
Carbohydrates, lipids, and molecular conjugates & misfolding, aggregation & Advanced glycation end-products (AGE), \\
& lipofuscin, aggrosomes & {$[26-30]$} \\
\hline
\end{tabular}


modifications. The so-called mechanistic theories of biological aging have often focused on a single category of inducers of molecular damage as an explanation for possible mechanisms of aging. Of these, two theories which have been the basis of most of the experimental biogerontology research are the free radical- and the protein error-theories of aging. Although neither of them can be considered to be the complete theory of biological aging, their contributions in providing a solid scientific footing to experimental aging research and anti-aging interventions cannot be overestimated.

\section{Free radical theory of aging (FRTA)}

FRTA, proposed in 1956, arose from a consideration of the aging phenomenon from the premise that a single common biochemical process may be responsible for the aging and death of all living beings (for an update, see [31]). There is abundant evidence to show that a variety of ROS and other FR are indeed involved in the occurrence of molecular damage which can lead to structural and functional disorders, diseases and death. The chemistry and biochemistry of FR is very well worked out, and the cellular and organismic consequences are well documented [32]. However, the main criticisms raised against this theory are with respect to its lack of incorporation of the essential and beneficial role of FR in the normal functioning and survival of biological systems [33,34]. Additionally, FRTA presents FR as the universal cause of damage without taking into account the differences in the wide range of FR-counteracting mechanisms in different species. Furthermore, a large body of data showing the contrary and/or lack of predictable and expected beneficial results of anti-oxidant and FR-scavenging therapies have restricted the FRTA to being only a partial explanation of some of the observed changes during aging [35-37].

\section{Protein error theory of aging (PETA)}

The history of PETA, also known as the error catastrophe theory, is full of controversy and premature declaration of its demise $[19,38,39]$. Since the spontaneous error frequency in protein translation is generally several orders of magnitude higher than that in DNA replication and RNA transcription, the role of protein errors and their feedback in biochemical pathways has been considered to be a crucial one with respect to aging. Several attempts have been made to determine the accuracy of translation in cell-free extracts, and most of the studies show that there is an age-related increase in the mis-incorporation of nucleotides and amino acids $[19,38,39]$. It has also been shown that there is an age-related accumulation of aberrant DNA polymerases and other components of the transcriptional and translational machinery $[19,38-42]$.
Further evidence in support of PETA comes from experiments which showed that an induction and increase in protein errors can accelerate aging in human cells and bacteria $[19,38,39,43,44]$. Similarly, an increase in the accuracy of protein synthesis can slow aging and increase the lifespan in fungi [45-47]. Therefore, it is not ruled out that several kinds of errors in various components of protein synthetic machinery, including tRNA charging, and in mitochondria do have long term effects on cellular stability and survival [48-51]. However, almost all these methods have relied on indirect in vitro assays, and so far direct, realistic and accurate estimates of agerelated changes in errors in cytoplasmic and mitochondrial proteins, and their biological relevance, have not been made. Similarly, applying methods such as two-dimensional gel electrophoresis, which can resolve only some kinds of mis-incorporations, have so far remained insensitive and inconclusive $[19,38,39]$. It will be necessary to combine several methods, such as electrophoresis, mass-spectrometry, protein-protein interactions and antibody-based detection of molecular heterogeneity to find out the extent of protein errors and their biological role in aging.

\section{From FRTA and PETA to higher order theories}

Both the FRTA and PETA provide molecular mechanisms for the occurrence of molecular damage. Additionally, nutritional components, specially the sugars and metal-based micronutrients can induce, enhance and amplify the molecular damage either independently or in combination with other inducers of damage. The biological consequences of increased levels of molecular damage are wide ranging and include altered gene expression, genomic instability, mutations, molecular heterogeneity, loss of cell division potential, cell death, impaired intercellular communication, tissue disorganization, organ dysfunctions, and increased vulnerability to stress and other sources of disturbance. Historically, each of these biological consequences has been used as the basis of putting forward other theories of aging, such as replicative senescence theory, neuroendocrine theory, pineal gland theory, immunological theory and many more $[7,34,52]$.

\section{Genetics, post-genetics and epigenetics of aging}

Since all molecular processes in a living system are based in and regulated by genes, an attractive research strategy has been to discover genes for aging, termed gerontogenes [53-55]. However, the evolutionary explanation for the origin of aging and limited lifespan discussed above have generally ruled out the notion of any specific genetic programme involving specific gerontogenes. But a lack of specific gerontogenes with the sole purpose of causing aging and terminating the 
lifespan of an individual does not imply that genes do not or cannot influence survival, longevity and the rate of aging.

There is ample evidence from studies performed on yeast and other fungi, nematodes, insects, rodents and humans that mutations in various genes can either prolong or shorten the lifespan, and some of these are also the cause of premature aging syndromes in human beings [56-58]. Additionally, genetic linkage studies for longevity in mice have identified major histocompatibility complex regions [59], and quantitative trait loci on several chromosomes [60,61] as putative genes for aging. In gene association studies with human centenarians, certain alleles of HLA locus on chromosome 6 [59], regions of chromosome 4 [62], different alleles of APO-E and APO-B, and DD genotype of angiotensin converting enzyme (ACE) have been linked to exceptional longevity. Similarly, several other studies have reported an association between human longevity and single nucleotide polymorphisms (SNP) in a variety of genes in various biological pathways, including heat shock response, mitochondrial functions, immune response, cholesterol metabolism and others [58,63-67].

An analysis of the various functions of the genes associated with aging and longevity shows that these genes cover a wide range of biochemical pathways, such as energy metabolism, kinases, kinase receptors, transcription factors, DNA helicases, membrane glucosidases, GTP-binding protein coupled receptors, chaperones, and cell cycle check point pathways [5658]. What is clear from the identification of the genes influencing aging and longevity is that whatever their normal function and mechanism of action may be, these gerontogenes did not evolve to cause and accumulate molecular damage, to cause functional disorders, and to terminate the life of the organism.

Most of these genes have well defined roles in normal metabolism, in intra- and inter-cellular signaling, and in maintenance and repair functions including stress response. It is the damage-induced changes in the regulation, structure and/or activity of their gene products which result in their altered biological role with age. Therefore, such genes have been termed "virtual gerontogenes" [54,68]. Furthermore, a lack of evolutionary selection of virtual gerontogenes has given rise to the notion of postgenetics or "post-reproductive genetics" as an explanation for different biological roles played at different ages by the same genetic variants [69].

\section{Epigenetics of aging}

Although genes are the foundation of life, genes in themselves are non functional entities. It is the wide variety of gene products, including coding and noncoding RNAs, proteins and other macromolecules, which constitute the biochemical and biophysical milieu for life to exist. "Epigenetics" is the most commonly used term to account for and to explain the consequences of the intracellular and extracellular milieu which establish and influence the structural and functional stability of genes $[2,70]$. These epigenetic effects and alterations generally remain uninherited from one generation to the next, but have strong deterministic effects on the health, survival and aging of the individual.

So far, there is only scanty information available about the involvement in aging of various intracellular epigenetic markers such as methylated cytosines, oxidatively modified nucleotides, alternatively spliced RNAs, and post-translationally modified proteins, including protein folding [71]. The full spectrum of epigenetics of aging is yet to be unraveled and at present is one of the most attractive and challenging areas of research in biogerontology [72,73]. A major reason for apparent difficulties in fully understanding the epigenetics of aging is the existence of several orders of higher complexity and diversity of the constituting components, such as physical, chemical, biological and environmental factors, including psychological factors in human beings. Furthermore, in order to understand how various conditions influence, regulate and modulate the actions, interactions and networks of gene products during aging will require new intellectual and technical tools, such as systems analysis, bioinformatics, and functional genomics involving simultaneous multiple analyses.

\section{Failure of homeodynamics and aging}

Another approach in developing a unified theory of aging is based in the basic characteristic of biological systems called homeostasis or homeodynamics. All living systems, have the intrinsic ability to respond, to counteract and to adapt to the external and internal sources of disturbance. The traditional conceptual model to describe this property is homeostasis, which has dominated biology, physiology and medicine since the 1930s. However, advances made in our understanding of the processes of biological growth, development, maturation, reproduction, and finally, of aging, senescence and death have led to the realization that the homeostasis model as an explanation is seriously incomplete. The main reason for the incompleteness of the homeostasis model is its defining principle of "stability through constancy", which does not take into account the new themes, such as cybernetics, control theory, catastrophe theory, chaos theory, information and interaction networks, that comprise and underline the modern biology of complexity. Since the 1990s, the term homeodynamics [74], is being increasingly used. The concept of homeodynamics accounts for the fact that the internal milieu of complex biological systems is not permanently fixed, is not at equilibrium, and is a dynamic regulation and interaction among various levels of organization. 
In parallel with the development of the concept of homeodynamics, another term allostasis has also been gaining recognition and use [75]. According to this model, "stability through change" is the most realistic situation for living systems. Allostasis model also takes into account the characteristics such as reciprocal trade-offs between various cells, tissues and organs, accommodative sensing and prediction with respect to the severity of a potential stressor, and the final cost of making a response and readjustment to bring about the necessary change. Aging, senescence and death are the final manifestations of unsuccessful homeodynamics or failure of allostasis $[2,76]$.

Table II gives a list of the key biochemical and physiological pathways and processes operating in cells, tissues and organ systems, and which are quintessential components of the homeodynamic machinery.

Of course, all these processes involve genes whose products and their interactions give rise to a "homeodynamic space" or the "buffering capacity", which is the ultimate determinant of an individual's chance and ability to survive and maintain a healthy state [76]. At present, our knowledge about the number of genes and their variants, their multiple interactions and consequences is too meagre to identify, define and manipulate the homeodynamic machinery in any sensible way.

Theoretically, it may be possible to design or engineer much better protected and better performing homeodynamic processes, and thus make organismic survival extended indefinitely. However, arguments based on the allocation of energy and metabolic resources (EMR) as the determinants of an organism's longevity and survival potential rule out such simplistic interventions [9,34]. According to these arguments, available EMR must be partitioned

Table II. Main pathways of maintenance and repair homeodynamics (modified from [2]).

\begin{tabular}{lc}
\hline Biological pathway & Selected references \\
\hline $\begin{array}{l}\text { 1. Multiple pathways of nuclear } \\
\text { and mitochondrial DNA repair. }\end{array}$ & {$[77-79]$} \\
$\begin{array}{l}\text { 2. Processes for sensing and } \\
\text { responding to intra- and } \\
\text { extra-cellular stressors. }\end{array}$ & {$[80-84]$} \\
$\begin{array}{l}\text { 3. Pathways for protein repair. } \\
\text { 4. Pathways for the removal } \\
\text { and turnover of defective proteins. }\end{array}$ & {$[85,86]$} \\
$\begin{array}{l}\text { 5. Antioxidative and enzymic defences } \\
\text { against reactive oxygen species. }\end{array}$ & {$[36,89-92]$} \\
$\begin{array}{l}\text { 6. Processes for the detoxification } \\
\text { of harmful chemicals in the diet. }\end{array}$ & {$[93-95]$} \\
$\begin{array}{l}\text { 7. Cellular and humoral immune } \\
\text { responses against pathogens and } \\
\text { parasites, including apoptosis. }\end{array}$ & {$[96-100]$} \\
$\begin{array}{l}\text { 8. Processes of wound healing } \\
\text { and tissue regeneration. }\end{array}$ & \\
\hline
\end{tabular}

between three fundamental features of life: (1) the basic metabolism, which includes biochemical synthesis, respiration, cell turnover, movement, feeding, digestion and excretion; (2) the reproduction; and (3) the maintenance through homeodynamic machinery as described above.

Whereas the basic metabolism is essential for all animals, the extent of investment in reproduction and maintenance can vary between species. This is the trade-off, which is the basis of the disposable soma theory of aging, between investment in maintenance and investment in reproduction, which are related inversely $[9,34]$. The evolved balance between the two depends on the life history strategy and ecological niche of the species. Several comparative studies have reported positive correlations between lifespan and the ability to repair DNA, to detoxify reactive oxygen molecules, to respond and counteract stress, and to replace worn-out cells [7]. In addition, negative correlation has been demonstrated between longevity and the rate of damage accumulation, including mutations, epimutations, macromolecular oxidation and aggregation of metabolic byproducts $[9,34]$.

The evolved nature of the homeodynamic machinery, in accordance with the life history traits of different species, sets an intrinsic genetic limit on the ELS, as described above. Therefore, the main cause of age-related accumulation of molecular damage is the inefficiency and failure of maintenance, repair and turnover pathways. Several theoretical and mathematical models are being developed in order to understand the interactive nature of the biological networks and trade-offs $[103,104]$. Similarly, the reliability theory of aging and longevity discusses the inevitable failure of complex systems such as cells and organisms [105], and reiterates the principle that no process can be one-hundred-percent accurate one-hundred-percent of the time; and it is the interactive nature of genes, milieu and chance that effectively determines how long homeodynamic ability can keep a biological system alive.

\section{Implications for aging intervention, prevention and therapies}

According to the homeodynamics-based explanations for aging and longevity described above, occurrence of aging in the period beyond ELS, and the onset of one or more diseases before eventual death, appear to be the evolutionary "default" setting. This viewpoint makes interventions in aging different from the treatment of one or more specific diseases. Also, although single or serial replacement of non-functional or dysfunctional body parts with natural or synthetic parts made of more durable material may provide a temporary solution to the problems of agerelated impairments, it does not modulate the underlying complex aging process as such [6]. 
Scientific and rational anti-aging strategies have the aim to slow down aging, to prevent and/or delay the physiological decline, and to regain lost functional abilities. Strengthening, improving or enlarging the homeodynamic space or the buffer capacity at the level of all genes comprising the homeodynamic machinery of an individual may be the ideal anti-aging remedy. However, such a gene-therapy approach for gerontomodulation requires redesigning the blueprint for structural and functional units of the body at the level of genes, gene products, macromolecular interactions, molecular-milieu interactions, and so on. Considering how little information and knowledge we have at present about all those interacting variants of genes, molecules, milieu and chance, it is not clear what this approach really means in practical and achievable terms.

Improving the milieu in which the homeodynamic machinery operates is the other strategy that is being followed by the majority of the practitioners of the socalled anti-aging medicine. Some of the main approaches are supplementation with hormones including growth hormone, dehydroepiandrosterone, melatonin and estrogen, and nutritional supplementation with synthetic and natural antioxidants in purified form or in extracts prepared from plant and animal sources [5]. Although some of these approaches have been shown to have some clinical benefits in the treatment of some diseases in the elderly, none of these really modulate the aging process itself. Furthermore, claims for the benefits of intake of high doses of vitamins and various antioxidants and their supposed anti-aging and lifeprolonging effects have very little scientific evidence to back them $[6,106]$. In contrast to this, nutritional modulation through caloric restriction (CR) has been shown to be an effective anti-aging and longevity extending approach in rodents and monkeys, with possible applications to human beings. But, this is a highly debatable issue at present both in terms of the practicalities of defining CR and of applying CR in human beings in physiological and evolutionary contexts [107-109].

A more realistic and promising approach in aging intervention and prevention is based in making use of an organism's intrinsic homeodynamic property of self maintenance and repair. It has been suggested that if cells and organisms are exposed to brief periods of stress so that their stress response-induced gene expression is upregulated and the related pathways of maintenance and repair are stimulated, one should observe anti-aging and longevity-promoting effects. Such a phenomenon in which stimulatory responses to low doses of otherwise harmful conditions improve health and enhance lifespan is known as hormesis $[6,110]$.

Mild stresses that have been reported to delay aging and prolong longevity in various systems include temperature shock, irradiation, heavy metals, prooxidants, acetaldehyde, alcohols, hypergravity, exercise and food restriction [6,110]. Hormesis-like beneficial effects of episodic and chronic, but mild, undernutrition have been reported for human beings. Intermittent fasting has been reported to have beneficial effects on glucose metabolism and neuronal resistance to injury. Although at present there are only a few studies performed which utilize mild stress as a modulator of aging and longevity, hormesis can be a useful experimental approach in biogerontology.

\section{Recapitulation}

Living systems survive by virtue of a set of defensive maintenance and repair systems which comprise their homeodynamic ability. A large number of interacting genes and genetic networks constitute this machinery, the exact details of which are yet to be unravelled. Successful homeodynamics is crucial for the growth, development and maturation of an organism until the reproduction and continuation of generations is assured. Homeodynamics is thus a longevity assurance mechanism, whose strength, efficiency and range have evolved in accordance with the evolutionary history of the species. Survival beyond the ELS of a species is necessarily accompanied by the progressive accumulation of random molecular damage. The progressive failure of homeodynamics leads to the physiological malfunctioning manifested as a general functional decline, diseases and ultimate death. A unified theory of biological aging involving genes, milieu and chance is emerging, maturing and acquiring a definitive shape, and can be the basis of aging intervention, prevention and modulation.

\section{Acknowledgements}

Laboratory of Cellular Ageing (LCA) is supported by grants from the Danish Research Councils (FNU and FSS), EU-Biomed programme "Proteomage", and Senetek PLC.

\section{References}

[1] Medvedev ZA. An attempt at a rational classification of theories of ageing. Biol Rev 1990;65:375-398.

[2] Holliday R. Aging is no longer an unsolved problem in biology. Ann NY Acad Sci 2006;1067:1-9.

[3] Holliday R. Ageing research in the next century. Biogerontology 2000;1:97-101.

[4] Rattan SIS. Biogerontology: The next step. Ann NY Acad Sci 2000;908:282-290.

[5] Rattan SIS. Aging Interventions and Therapies. Singapore: World Scientific Publishers; 2005.

[6] Rattan SIS. Anti-ageing strategies: Prevention or therapy? EMBO Reports 2005;6:S25-S29.

[7] Rattan SIS, Clark BFC. Understanding and modulating ageing. IUBMB Life 2005;57:297-304. 
[8] Carnes BA, Olshansky SJ, Grahn D. Biological evidence for limits to the duration of life. Biogerontology 2003;4:31-45.

[9] Kirkwood TBL. Time of Our Lives. London: Weidenfeld \& Nicolson; 1999.

[10] Kirkwood TBL. Evolution of ageing. Mech Ageing Dev 2002;123:737-745.

[11] Austad SN. Why We Age. New York: John Wiley \& Sons, Inc. 1997.

[12] Rose MR. Will human aging be postponed? Sci Amer 2004; 14:24-29.

[13] Martin GM. The Werner mutation: Does it lead to a "public" or "private" mechanism of aging? Mol Med 1997;3: 356-358.

[14] de Grey ADNJ. The Mitochondrial Free Radical Theory of Aging. Austin, TX, USA: R.G. Landes Co. 1999.

[15] Lombard DB, Chua KF, Mostoslavsky R, Franco S, Gostissa $\mathrm{M}$, Alt FW. DNA repair, genome stability, and aging. Cell 2005;120:497-512.

[16] Wallace DC. A mitochondrial paradigm of metabolic and degenerative diseases, aging, and cancer: A dawn for evolutionary medicine. Ann Rev Genet 2005;39:359-407.

[17] Loeb LL, Wallace DC, Martin GM. The mitochondrial theory of aging and its relationship to reactive oxygen species damage and somatic mtDNA mutations. Proc Natl Acad Sci USA 2005;102:18769-18770.

[18] Singh KK. Mitochondria damage checkpoint, aging, and cancer. Ann NY Acad Sci 2006;1067:182-190.

[19] Rattan SIS In: von Zglinicki T, editor. Transcriptional and translational dysregulation during aging. Dordrecht: Kluwer Academic Publishers; 2003. p 179-191.

[20] Baynes JW. From life to death-the struggle between chemistry and biology during aging: The Maillard reaction as an amplifier of genomic damage. Biogerontology 2000; $1: 235-246$.

[21] Grune T. Oxidative stress, aging and the proteasomal system. Biogerontology 2000;1:31-40.

[22] Grune T, Jung T, Merker K, Davies KJA. Decreased proteolysis caused by protein aggeregates, inclusion bodies, plaques, lipofuscin, ceroid, and "aggresomes" during oxidative stress, aging, and disease. Int J Biochem Cell Biol 2004;36:2519-2530.

[23] Stadtman ER, Levine RL. Free radical-mediated oxidation of free amino acids and amino acid residues in proteins. Amino Acids 2003;25:207-218.

[24] Cloos PA, Christgau S. Post-translational modifications of proteins: Implications for aging, antigen recognition, and autoimmunity. Biogerontology 2004;5:139-158.

[25] Rattan SIS. Translation and post-translational modifications during aging. In: Macieira-Coelho A, editor. Molecular Basis of Aging. Boca Raton, Florida: CRC Press; 1995. p 389-420.

[26] Niki E, Yoshida Y, Saito Y, Noguchi N. Lipid peroxidation: Mechansims, inhibition, and biological effects. Biochem Biophys Res Commun 2005;338:668-676.

[27] Suji G, Sivakami S. Glucose, glycation, and aging. Biogerontology 2004;5:375-381.

[28] Hallén A. Accumulation of insoluble protein and aging. Biogerontology 2002;3:307-315.

[29] Dukic-Stefanovic S, Schinzel R, Riederer P, Munch G. AGES in brain ageing: AGE-inhibitors as neuroprotective and anti-dementia drugs? Biogerontology 2001;2:19-34

[30] Stroikin Y, Dalen H, Brunk UT, Terman A. Testing the "garbage" accumulation theory of aging. mitotic acitivity protects cells fom death induced by inhibition of autophagy. Biogerontology 2005;6:39-47.

[31] Harman D. Free radical theory of aging: An update. Ann NY Acad Sci 2006;1067:10-21.

[32] Sitte $N$, von Zglinicki T. Free radical production and antioxidant defense: A primer. In: von Zglinicki $\mathrm{T}$, editor.
Aging at molecular level. Dordrecht: Kluwer Academic Publishers; 2003. p 1-10.

[33] Sohal RS. The free radical theory of aging: A critique. Rev Biol Res Aging 1987;3:431-449.

[34] Holliday R. Understanding Ageing. Cambridge, UK: Cambridge University Press; 1995.

[35] Le Bourg E, Fournier D. Is lifespan extension accompanied by improved antioxidant defences? A study of superoxide dismutase and catalase in Drosophila melanogaster flies that lived in hypergravity at young age. Biogerontology 2004;5: $261-264$

[36] Le Bourg E. Antioxidants and aging in human beings. In: Rattan SIS, editor. Aging Interventions and Therapies. Singapore: World Scientific Publishers; 2005. in press.

[37] Howes RM. The free radical fantasy: A panoply of paradoxes. Ann NY Acad Sci 2006;1067:22-26.

[38] Holliday R. The current status of the protein error theory of aging. Exp Gerontol 1996;31:449-452.

[39] Rattan SIS. Synthesis, modifications and turnover of proteins during aging. Exp Gerontol 1996;31:33-47.

[40] Fukuda M, Taguchi T, Ohashi M. Age-dependent changes in DNA polymerase fidelity and proofreading activity during cellular aging. Mech Ageing Dev 1999;109:141-151.

[41] Srivastava VK, Miller S, Schroeder M, Crouch E, Busbee D. Activity of DNA polymerase alpha in aging human fibroblasts. Biogerontology 2000;1:201-216.

[42] Srivatsava VK, Busbee DL. Replicative enzymes and ageing: Importance of DNA polymerase alpha function to the events of cellular ageing. Ageing Res Rev 2002;1:443-463.

[43] Nyström T. Translational fidelity, protein oxidation, and senescence: Lessons from bacteria. Ageing Res Rev 2002;1: 693-703.

[44] Nyström T. Aging in bacteria. Curr Opin Microbiol 2002;5: 596-601.

[45] Silar P, Picard M. Increased longevity of EF-1 $\alpha$ high-fidelity mutants in Podospora anserina. J Mol Biol 1994;235: 231-236.

[46] Silar P, Rossignol M, Haedens V, Derhy Z, Mazabraud A. Deletion and dosage modulation of the eEF1A gene in Podospora anserina: effect on the life cycle. Biogerontology 2000;1:47-54.

[47] Holbrook MA, Menninger JR. Erythromycin slows aging of Saccharomyces cerevisiae. J Gerontol Biol Sci 2002;57A: B29-B36.

[48] Kowald A, Kirkwood TBL. Accuracy of tRNA charging and codon:anticodon recognition; relative importance for cellular stability. J theor Biol 1993;160:493-508.

[49] Kowald A, Kirkwood TBL. Mitochondrial mutations, cellular instability and ageing: Modelling the population dynamics of mitochondria. Mutat Res 1993;295:93-103.

[50] Hipkiss A. Errors, mitochondrial dysfunction and ageing. Biogerontology 2003;4:397-400.

[51] Holliday R. Streptomycin, errors in mitochondria and ageing. Biogerontology 2005;6:431-432.

[52] Rattan SIS. Ageing - a biological perspective. Molec Aspects Med 1995;16:439-508.

[53] Rattan SIS. Beyond the present crisis in gerontology. BioEssays 1985;2:226-228.

[54] Rattan SIS. Gerontogenes: Real or virtual? FASEB J 1995;9: 284-286.

[55] Johnson TE. A personal retrospective on the genetics of aging. Biogerontology 2002;3:7-12.

[56] Martin GM. Genetic modulation of senescent phenotypes in Homo sapiens. Cell 2005;120:523-532.

[57] Kenyon C. The plasticity of aging: Insights from long-lived mutants. Cell 2005;120:449-460.

[58] Christensen K, Johnson TE, Vaupel JW. The quest for genetic determinants of human longevity: Challenges and insights. Nature Rev Genet 2006;7:436-448. 
[59] Gelman R, Watson A, Bronson R, Yunis E. Murine chromosomal regions correlated with longevity. Genetics 1988;118:693-704.

[60] Miller RA, Chrisp C, Jackson AU, Burke D. Marker loci associated with life span in genetically heterogeneous mice. J Gerontol Med Sci 1998;53A:M257-M263.

[61] De Haan G, Gelman R, Watson A, Yunis E, Van Zant G. A putative gene causes variability in lifespan among gentoypically identical mice. Nat Genet 1998;19:114-116.

[62] Puca AA, Daly MJ, Brewster SJ, Matsie TC, Barrett J, SheaDrinkwater M, Kang S, Joyce E, Nicoli J, Benson E, Kunkel LM, Perls T. A genome-wide scan for linkage to human exceptional longevity identifies a locus on chromosome 4 . Proc Natl Acad Sci USA 2001;98:10505-10508.

[63] Altomare K, Greco V, Bellizzi D, Berardelli M, Dato S, DeRango F, Garasto S, Rose G, Feraco E, Mari V, Passarino G, Franceschi C, De Benedictis G. The allele (A)-110 in the promoter region of the HSP70-1 gene is unfavourable to longevity in women. Biogerontology 2003;4:215-220.

[64] Tan Q, De Benedictis G, Yashin AI, Bonafe M, DeLuca M, Valensin S, Vaupel JW, Franceschi C. Measuring the genetic influence in modulating the human life span: Geneenvironment interaction and the sex-specific genetic effect. Biogerontology 2001;2:141-153.

[65] Singh R, Kølvraa S, Bross P, Gregersen N, Nexø BA, Frederiksen H, Christensen K, Rattan SIS. Association between low self-rated health and heterozygosity for -110A-C polymorphism in the promoter region of HSP70-1 in aged Danish twins. Biogerontology 2004;5:169-176.

[66] Bessenyei B, Marka M, Urban L, Zeher M, Semsei I. Single nucleotide polymorphisms: Aging and diseases. Biogerontology 2004;5:291-300.

[67] Atzmon G, Rincon M, Rabizadeh P, Barzilai N. Biological evidence for inheritance of exceptional longevity. Mech Age Dev 2005; 126:341-345.

[68] Rattan SIS. The nature of gerontogenes and vitagenes. Antiaging effects of repeated heat shock on human fibroblasts. Annal NY Acad Sci 1998;854:54-60.

[69] Franceschi C, Olivieri F, Marchegiani F, Cardelli M, Cavallone L, Capri M, Salvioli S, Valensin S, De Benedictis G, Di Iorio A, Caruso C, Paolisso G, Monti D. Genes involved in immune response/inflammation, IGF/insulin pathway and response to oxidative stress play a major role in the genetics of human longevity: The lesson of centenarians. Mech Age Dev 2005;126:351-361.

[70] Holliday R. DNA modification to epigenetics. J Genet 1998; $77: 65-69$.

[71] Lund AH, van Lohuizen M. Epigenetics and cancer. Genes \& Dev 2004;18:2315-2335.

[72] Issa JP. Epigenetic variation and human disease. J Nutr 2002; 132:2388S-2392S.

[73] Bandyopadhyay D, Medrano EE. The emerging role of epigenetics in cellular and organismal aging. Exp Gerontol 2003;38:1299-1307.

[74] Yates FE. Order and complexity in dynamical systems: Homeodynamics as a generalized mechanics for biology. Math Comput Model 1994;19:49-74.

[75] Schulkin J, editor. Allostasis, homeostasis, and the costs of adaptation. Cambridge, UK: Cambridge University Press; 2004.

[76] Rattan SIS. Homeostasis, homeodynamics, and aging. Encyclopedia of Gerontology 2006; in press.

[77] Lindahl T, Wood RD. Quality control by DNA repair. Science 1999;286:1897-1905.

[78] Bohr VA. Repair of oxidative DNA damage in nuclear and mitochondrial DNA, and some changes with aging in mammalian cells. Free Rad Biol Med 2002;32:804-812.

[79] Bürkle A. Physiology and pathophysiology of poly(ADPribosyl)ation. BioEssays 2001;23:795-806.
[80] Basu S, Srivastava PK. Heat shock proteins: The fountainhead of innate and adaptive immune responses. Cell Stress \& Chaperones 2000;5:443-451.

[81] Gutzeit HO. Interaction of stressors and the limits of cellular homeostasis. Biochem Biophys Res Commun 2001;283: $721-725$.

[82] von Zglinicki T, Bürkle A, Kirkwood TBL, Stress. DNA damage and ageing - an integrative approach. Exp Gerontol 2001;36:1049-1062.

[83] Verbeke P, Fonager J, Clark BFC, Rattan SIS. Heat shock response and ageing: Mechanisms and applications. Cell Biol Int 2001;25:845-857.

[84] Temple MD, Perrone GG, Dawes IW. Complex cellular responses to reactive oxygen species. Trends Cell Biol 2005; 15:319-326.

[85] Mary J, Vougier S, Picot CR, Perichon M, Petropoulos I, Friguet B. Enzymatic reactions involved in the repair of oxidized proteins. Exp Gerontol 2004;39:1117-1123.

[86] Brégégére F, Milner Y, Friguet B. The ubiquitin-proteasome system at the crossroads of stress-response and ageing pathways: A handle for skin care? Aging Res Rev 2006;5: $60-90$.

[87] Carrard G, Bulteau AL, Petropoulos I, Friguet B. Impairment of proteasome structure and function in aging. Int $\mathrm{J}$ Biochem Cell Biol 2002;34:1461-1474.

[88] Martinez-Vicente M, Sovak G, Cuervo AM. Protein degradation and aging. Exp Gerontol 2005;40:622-633.

[89] Halliwell B. The antioxidant paradox. Lancet 2000;355: $1179-1180$.

[90] Azzi A, Davies KJA, Kelly F. Free radical biology terminology and critical thinking. FEBS Lett 2004;558:3-6.

[91] Ray G, Husain SA. Oxidants, antioxidants and carcinogenesis. Ind J Exp Biol 2002;40:1213-1232.

[92] Sen CK, Packer L, Hänninen O. Handbook of Oxidants and Antioxidants in Exercise. Amsterdam, The Netherlands: Elsevier; 2000. p 1207.

[93] Jakoby WB, Ziegler DM. The enzymes of detoxication q. J Biol Chem 1990;265:20715-20718.

[94] Porter TD, Coon MJ. Cytochrome P-450. Multiplicity of isoforms, substrates, and catalytic and regulatory mechanisms. J Biol Chem 1991;266:13469-13472.

[95] Stadtman ER, Arai H, Berlett BS. Protein oxidation by the cytochrome P450 mixed-function oxidation system. Biochem Biophys Res Commun 2005;338:432-436.

[96] Janeway CA, Jr.. How the immune system works to protect the host from infection: A personal view. Proc Natl Acad Sci USA 2001;98:7461-7468.

[97] Aspinall R. Longevity and the immune response. Biogerontology 2000;1:273-278.

[98] Effros RB. Genetic alterations in the ageing immune system: Impact on infection and cancer. Mech Ageing Dev 2003;124: 71-77.

[99] Padgett RW, Glaser R. How stress influences the immune response. Trends Immunol 2003;24:444-448.

[100] Pawelec G. Immunosensence and human longevity. Biogerontology 2003;4:167-170.

[101] Ashcroft GS, Mills SJ, Ashwoth JJ. Ageing and wound healing. Bigerontology 2002;3:337-345.

[102] Jenkins G. Molecular mechanisms of skin ageing. Mech Ageing Dev 2002;123:801-810.

[103] Goldberger AL, Amaral LA, Hausdorff JM, Ivanov P, Peng CK, Stanley HE. Fractal dynamics in physiology: Alterations with disease and aging. Proc Natl Acad Sci USA 2002;99: $2466-2472$

[104] Raghothama C, Harsha HC, Prasad CK, Pandey A. Bioinformatics and proteomics approaches for aging research. Biogerontology 2005;6:227-232.

[105] Gavrilov LA, Gavrilova NS. The reliability theory of aging and longevity. J Theor Biol 2001;213:527-545. 
[106] Olshansky SJ, Hayflick L, Carnes BA. No truth to the fountain of youth. Sci Amer 2002;286:92-95.

[107] Demetrius L. Calorie restricition, metabolic rate and entropy. J Gerontol Biol Sci 2004;59A:902-915.

[108] Olshansky SJ, Rattan SIS. At the heart of aging: Is it metabolic rate or stability? Biogerontology 2005;6:291-295.
[109] Le Bourg E, Rattan SIS. Can dietary restriction increase longevity in all species, particularly in human beings? Introduction to a debate among experts. Biogerontology $2006 ; 7$.

[110] Rattan SIS. Aging intervention, prevention, and therapy through hormesis. J Gerontol Biol Sci 2004;59A:705-709. 